\title{
Polinização de Spondias tuberosa Arruda (Anacardiaceae) e análise da partilha de polinizadores com Ziziphus joazeiro Mart. (Rhamnaceae), espécies frutíferas e endêmicas da caatinga
}

\author{
TARCILA DE LIMA NADIA ${ }^{1,3}$, ISABEL CRISTINA MACHADO² e \\ ARIADNA VALENTINA LOPES ${ }^{2}$
}

(recebido: 23 de fevereiro de 2006; aceito: 7 de dezembro de 2006)

\begin{abstract}
Pollination of Spondias tuberosa Arruda (Anacardiaceae) and analysis of pollinators share with Ziziphus joazeiro Mart. (Rhamnaceae), fruit species endemic to the "caatinga"). Spondias tuberosa Arruda, an endemic species of "caatinga", has a great economic importance, because its fruits are highly commercialized. Nevertheless, there are no researches concerning floral and pollination biology of this species, that would be important to agriculture research. The objective of this study was to analyse the reproductive phenology, floral biology and pollination of Spondias tuberosa, and to compare the similarity of its pollinators with those of Ziziphus joazeiro Mart., in the "caatinga". This study was carried out in the municipality of Boa Vista, Paraíba State, Brazil. The flowering and fruiting season occurred at the end of dry season and during the whole wet season, respectively. Spondias tuberosa is andromonoecious and possess hermaphrodites and male flowers on the same inflorescence. The flowers are white and have two groups of stamens. The hermaphrodite flowers have a pentacarpelar gynoecium with a single ovule while the male flowers present a pistiloid. Flower opening changes according to development stage of the inflorescence. The majority of hermaphrodite flowers open on the initial development stage. The anthesis began at 5:00h, lasting two days to hermaphrodite flowers and one day to male flowers. Eight species of wasps, six of bees and four of flies were registered visiting flowers of Spondias tuberosa. Scaptotrigona postica flavisetis Moure, Trigona fuscipennis Friese (Apidae) and Polybia ignobilis Haliday (Vespidae) were the mainly pollinators. The similarity between the pollinators of Spondias tuberosa and Ziziphus joazeiro was low, suggesting that the reproductive success of theses species was not affected by pollinator's share, despite the fact that flowering occur at the same time.
\end{abstract}

Key words - andromonoecy, caatinga, reproduction, Spondias tuberosa, umbuzeiro

RESUMO - (Polinização de Spondias tuberosa Arruda (Anacardiaceae) e análise da partilha de polinizadores com Ziziphus joazeiro Mart. (Rhamnaceae), espécies frutíferas e endêmicas da caatinga). Spondias tuberosa Arruda, espécie endêmica da caatinga, apresenta grande importância econômica, pois seus frutos são bastante comercializados. Apesar de sua importância, não há estudos que tratem da biologia floral e da polinização dessa espécie, que são básicos para pesquisas em agricultura. Nesse trabalho, foram analisados aspectos da fenologia reprodutiva, biologia floral e polinização de Spondias tuberosa, bem como o grau de similaridade entre seus polinizadores e os de Ziziphus joazeiro Mart., no Município de Boa Vista, Paraíba, Brasil. A floração e a frutificação ocorreram no fim da estação seca e durante todo o período chuvoso, respectivamente. Spondias tuberosa é andromonóica, possuindo flores hermafroditas e masculinas em uma mesma inflorescência. As flores são brancas e apresentam dois grupos de estames. As flores hermafroditas possuem gineceu pentacarpelar com um único óvulo e as masculinas apresentam pistilódio. A abertura das flores variou de acordo com o estádio de desenvolvimento da inflorescência, abrindo a maior parte das flores hermafroditas nos estádios iniciais. A antese iniciou às 5h00, tendo duração de dois dias em flores hermafroditas e de um dia nas masculinas. Foram registradas oito espécies de vespas, seis de abelhas e quatro de moscas visitando as flores de Spondias tuberosa, sendo as espécies Scaptotrigona postica flavisetis Moure, Trigona fuscipennis Friese (Apidae) e Polybia ignobilis Haliday (Vespidae) as principais polinizadoras. A similaridade entre os visitantes florais de Spondias tuberosa e Ziziphus joazeiro foi baixa, sugerindo que o sucesso reprodutivo das espécies não foi afetado pela partilha de polinizadores, apesar da floração ter ocorrido na mesma época.

Palavras-chave - andromonoicia, caatinga, reprodução, Spondias tuberosa, umbuzeiro

\section{Introdução}

A família Anacardiaceae tem distribuição pantropical, sendo constituída por cerca de 80 gêneros

\footnotetext{
1. Universidade Federal de Pernambuco, Programa de PósGraduação em Biologia Vegetal, 50372-970 Recife, PE, Brasil.

2. Universidade Federal de Pernambuco, Departamento de Botânica, 50372-970 Recife, PE, Brasil.

3. Autor para correspondência: tarcinadia@yahoo.com.br
}

e 600 espécies, dos quais cerca de 13 gêneros e 68 espécies ocorrem no Brasil (Barroso 1991). Muitas espécies de Anacardiaceae são conhecidas por serem plantas frutíferas de alto valor econômico (Anacardium occidentale L., caju; Mangifera indica L., manga; Pistacia vera L., pistache; Spondias cytherea Sonn., cajá-manga; S. mombim L., cajá; S. purpurea L., cirigüela; S. tuberosa Arruda, umbu), por produzirem boa madeira (Astronium fraxinifolium Schott, A. 
lecointein Ducke, muiraquatiara; A. urundeuva Engl., aroeira; Schinopsis brasiliensis Engl., baraúna; Schinus terebinthifolius Raddi) ou substâncias usadas na indústria e na medicina (Pistacia cabulica Stocks, P. lentiscus L., Schinopsis lorentzii (Griseb.) Engl.) (Barroso 1991, Barros 1995).

Spondias tuberosa é endêmica do semi-árido brasileiro (Drumond et al. 2001, Giulietti et al. 2002), ocorrendo desde o Piauí até o Norte de Minas Gerais (Epstein 1998, Lorenzi 1998). Conhecida popularmente como umbuzeiro ou imbuzeiro, apresenta muitas utilidades econômicas, sendo seu fruto comercializado in natura ou em forma de polpa (Lederman et al. 1992, Cavalcanti et al. 2000). Pode ser cultivada em larga escala, tanto para a alimentação humana, quanto para suplementação alimentar de animais (Cavalcanti et al. 2000). Suas raízes e folhas também podem ser utilizadas como alimento, e a água armazenada nas raízes é utilizada na medicina popular (Epstein 1998). Além da importância econômica, $S$. tuberosa apresenta grande valor ecológico, fornecendo recursos florais, tais como néctar e pólen, bem como local de nidificação para algumas abelhas da tribo Meliponini (Marinho et al. 2002).

Devido à sua importância econômica, estudos foram realizados visando o cultivo, desenvolvimento, colheita e processamento dos frutos de $S$. tuberosa (Epstein 1998, Cavalcanti et al. 1999, 2000). Apesar das várias pesquisas desenvolvidas acerca do aproveitamento econômico de $S$. tuberosa, há carência de estudos sobre a biologia floral e a polinização dessa espécie. Estes estudos são importantes para a conservação da espécie, tendo em vista que S. tuberosa é explorada de forma extrativista em inúmeros locais de ocorrência natural sem que se conheçam os seus polinizadores e o grau de dependência dos mesmos na formação de frutos.

Ziziphus joazeiro Mart. (Rhamnaceae), outra espécie endêmica da caatinga (Giulietti et al. 2002), apresenta atributos florais semelhantes a Spondias tuberosa (Nadia 2005). Ambas são simpátricas e apresentam sobreposição no período de floração (Machado et al. 1997), fatos que, em conjunto com a semelhança nos atributos florais, podem levar à partilha de polinizadores (Campbell 1985) que, por sua vez, pode ou não afetar (positiva ou negativamente) o sucesso reprodutivo das espécies envolvidas (Schemske 1981, Campbell 1985).

Neste estudo objetivou-se, então, estudar a biologia floral e a ecologia de polinização de Spondias tuberosa, bem como analisar o grau de similaridade entre os seus visitantes florais e os de Ziziphus joazeiro (Rhamnaceae).

\section{Material e métodos}

Local de estudo - O estudo foi realizado na Fazenda Dona Soledade, entre os municípios de Boa Vista e Cabaceiras, Estado da Paraíba, Nordeste do Brasil (7²0’30,7" S e $36^{\circ} 18^{\prime} 5,8^{\prime \prime}$ W). A fazenda Dona Soledade é uma área particular com vegetação típica de caatinga, possuindo cerca de 690 ha. A região apresenta precipitação média anual de $330 \mathrm{~mm}$ e está localizada na Região do Cariri paraibano, onde o período chuvoso ocorre de fevereiro a maio (Governo da Paraíba 2005), havendo um longo período de estiagem (cerca de oito meses), apresentando o registro mais baixo de chuvas das caatingas (Prado 2003).

Fenologia reprodutiva e biologia floral - Foram marcados dez indivíduos de Spondias tuberosa para acompanhamento fenológico quinzenal, sendo utilizada metodologia de Fournier (1974) para quantificar a porcentagem de flores e frutos por indivíduo, obtendo-se, assim, a intensidade de floração e frutificação na população (Bencke \& Morellato 2002). As observações fenológicas foram realizadas no período de agosto de 2004 a julho de 2005. O padrão fenológico da floração apresentado nesse período foi classificado a partir das proposições de Gentry (1974) e Newstrom et al. (1994).

O número de flores por inflorescência foi quantificado, no campo, em quinze inflorescências ainda jovens de dez indivíduos diferentes, considerando as flores abertas e os botões. O desenvolvimento da inflorescência foi acompanhado contando-se o número de flores hermafroditas e masculinas que se abriam por dia. A distribuição dos diferentes tipos florais e suas proporções foram registradas considerando a base, o meio e o ápice da inflorescência, sendo a base formada pelas duas primeiras ramificações, o ápice pelas três últimas e o meio pelas demais ramificações da inflorescência entre a base e o ápice.

A longevidade floral foi acompanhada em flores hermafroditas e masculinas, marcando-se botões em préantese e acompanhando-os desde a sua abertura até a senescência. A receptividade do estigma foi verificada efetuando-se polinizações cruzadas em dez flores do primeiro e dez do segundo dia de dois indivíduos diferentes $(n=20)$, sendo estas coletadas após seis horas da polinização e fixadas em FAA com etanol 70\% (Dafni 1992). Posteriormente, estas flores foram coradas com azul de anilina, segundo técnica de Martin (1959), e analisadas sob microscópio de fluorescência para verificação da germinação de grãos de pólen. Para efetuar as polinizações cruzadas $(n=20)$, foram utilizados grãos de pólen de flores hermafroditas e masculinas separadamente. Cinco flores do primeiro e cinco do segundo dia receberam grãos de pólen oriundos de flores hermafroditas e as outras cinco flores do primeiro e do segundo dia receberam grãos de pólen oriundos de flores masculinas. 
Para verificar a emissão de odor, flores de três indivíduos foram colocadas em um recipiente de vidro com tampa, sendo destampados e cheirados após 30 minutos (Dafni 1992, Kearns \& Inouye 1993). Para localização e delimitação do nectário e das possíveis áreas de emissão de odor, dez flores previamente ensacadas, provenientes de cinco indivíduos, foram mergulhadas em solução de vermelho neutro, sendo observadas as partes florais coradas (Vogel 1990, Dafni 1992, Kearns \& Ynouye 1993). O volume e a concentração de açúcares no néctar não puderam ser mensurados devido à pequena quantidade produzida por flor (inferior a $1 \mu \mathrm{L}$ ).

Flores de Spondias tuberosa foram coletadas para análise da morfologia floral em laboratório, sob estereomicroscópio. O número de grãos de pólen de cada um dos dois tipos de antera, tanto de flores hermafroditas quanto de masculinas, foi obtido através de contagem direta com auxílio de lamínula quadriculada sob microscópio de luz. Para essa contagem, os grãos de pólen foram corados com carmim acético, tendo sido avaliada, concomitantemente, a viabilidade polínica (Radford et al. 1974). Estas análises foram feitas utilizando-se todas as 10 anteras de 16 botões em préantese (oito hermafroditas e oito masculinos) de quatro indivíduos diferentes.

Eficácia reprodutiva - Para observar o número de frutos formados por inflorescência sob condições naturais, foram marcadas 28 inflorescências e contado o número total de flores e de botões, sendo posteriormente calculado o número de flores hermafroditas para cada inflorescência através da proporção média de flores hermafroditas por inflorescência. Outras 10 inflorescências jovens foram ensacadas e, à medida em que as flores se abriam, foram realizadas polinizações cruzadas em cerca de $30 \%$ das flores hermafroditas de cada inflorescência, para detectar a capacidade suporte de frutos por inflorescência. A partir dos resultados desses dois tratamentos foi calculada a eficácia reprodutiva (Zapata \& Arroyo 1978). Para verificar a formação de frutos em função do doador de pólen, 20 flores, previamente ensacadas, de cinco indivíduos diferentes receberam grãos de pólen oriundos de flores hermafroditas, e outras vinte receberam de flores masculinas.

Visitantes florais e disponibilidade de pólen - O comportamento dos visitantes florais foi verificado diretamente em campo em plantas focais e também a partir da análise de fotografias. Os visitantes florais foram classificados como polinizadores efetivos, polinizadores ocasionais ou pilhadores, levando em consideração a morfologia do animal visitante, seu comportamento e sua freqüência. Espécimestestemunho dos visitantes florais foram coletados e montados à seco para identificação por especialistas, e, posteriormente, depositados na Coleção Entomológica do Laboratório de Biologia Floral e Reprodutiva, Universidade Federal de Pernambuco.

A freqüência dos visitantes florais foi calculada para dois indivíduos durante o início, pico e fim de floração. Foi considerado em início de floração o indivíduo que apresentava mais de $75 \%$ de botões florais, até $25 \%$ de flores abertas e nenhum fruto formado ou em desenvolvimento. Indivíduos em pico de floração apresentavam até $25 \%$ de botões florais, de $50 \%$ a $75 \%$ de flores abertas e até $25 \%$ de frutos em desenvolvimento. $\mathrm{O}$ fim de floração foi caracterizado por indivíduos que possuíam menos de $25 \%$ de flores abertas, pouco ou nenhum botão floral e mais de $75 \%$ de frutos formados ou em desenvolvimento.

A disponibilidade de pólen durante as visitas às flores de Spondias tuberosa foi verificada coletando-se duas flores de cada tipo floral a cada quatro horas após o início da antese até a senescência, totalizando 12 flores hermafroditas e seis flores masculinas. Os grãos de pólen de todas as anteras de cada flor foram retirados e colocados em lâmina histológica, corados com carmim acético e fixados com glicerina para posterior contagem sob estereomicroscópio.

A similaridade das guildas de visitantes florais de Spondias tuberosa e de Ziziphus joazeiro foi calculada utilizando-se o Coeficiente de Jaccard (Krebs 1989). Para verificar se a partilha de polinizadores afeta o sucesso reprodutivo dessas duas espécies, 58 inflorescências foram marcadas e deixadas livres para formação natural de frutos nas seguintes situações: (1) período em que apenas $S$. tuberosa estava em floração (novembro/2003, $n=13$ ); (2) período em que apenas $Z$. joazeiro estava em floração (fevereiro/2004, $n=15$ ); e (3) período em que as duas espécies estavam sincronicamente em floração (novembro/2004, $n=15$ para cada espécie).

Análises estatísticas - O teste de Mann-Whitney foi empregado para analisar diferenças entre o diâmetro da corola dos dois tipos florais. Para verificar se há diferença na quantidade de grãos de pólen em anteras de estames curtos e longos, bem como entre flores masculinas e hermafroditas foi empregado o teste Kruskal-Wallis (Sokal \& Rohlf 1995). O teste de Shapiro-Wilk (Sokal \& Rohlf 1995) foi aplicado para verificar a normalidade dos dados referentes ao número de flores hermafroditas e masculinas por inflorescência. Para testar a diferença entre o número de flores hermafroditas e masculinas por inflorescência foi utilizado o teste t para amostras relacionadas. Por último, foi aplicado o Teste Quiquadrado para verificar diferenças na formação de frutos entre os tratamentos referentes à eficácia reprodutiva, à polinização cruzada dependendo de doador de pólen e à partilha de polinizadores. Os testes estatísticos foram feitos com auxílio do programa BioEstat 3.0 (Ayres et al. 2003).

\section{Resultados}

Fenologia reprodutiva e biologia floral - Durante o período de observação, Spondias tuberosa floresceu entre os meses de novembro e fevereiro, período que corresponde ao fim da estação seca e início da chuvosa na área de estudo, com o pico no mês de dezembro e apresentando ainda alguns indivíduos com poucas flores 
nos meses de março e abril (figura 1). A frutificação iniciou-se também no mês de novembro, ainda na estação seca, estendendo-se por todo o período chuvoso, até o mês de maio. O pico de frutificação ocorreu nos meses de fevereiro e março, quando a maioria dos frutos atingiu a maturação, correspondendo ao início do período chuvoso.

Spondias tuberosa apresenta dois tipos de flores, hermafroditas e masculinas (figuras 2, 3) em um mesmo indivíduo, caracterizando o sistema sexual do tipo andromonóico. As inflorescências apresentaram, em média, 155 flores $( \pm 46,89)$, sendo $40 \%$ delas hermafroditas e $60 \%$ masculinas, não havendo diferença significativa. O número de flores abertas por inflorescência por dia variou de acordo com o estádio de desenvolvimento da mesma, sendo, em média, de nove flores por inflorescência por dia, podendo variar de uma a 26 flores. As inflorescências de $S$. tuberosa duraram, em média, sete dias, podendo variar de um a 11 dias. Mais de $70 \%$ das flores hermafroditas já haviam aberto do início até a metade do período de duração de uma inflorescência (considerando o início a partir da primeira flor aberta), enquanto que cerca de $60 \%$ das flores masculinas iniciaram a antese desse período em diante. A distribuição das flores na inflorescência variou, com ca. de $63 \%$ do total das flores masculinas concentradas na base da inflorescência, e ca. de $90 \%$

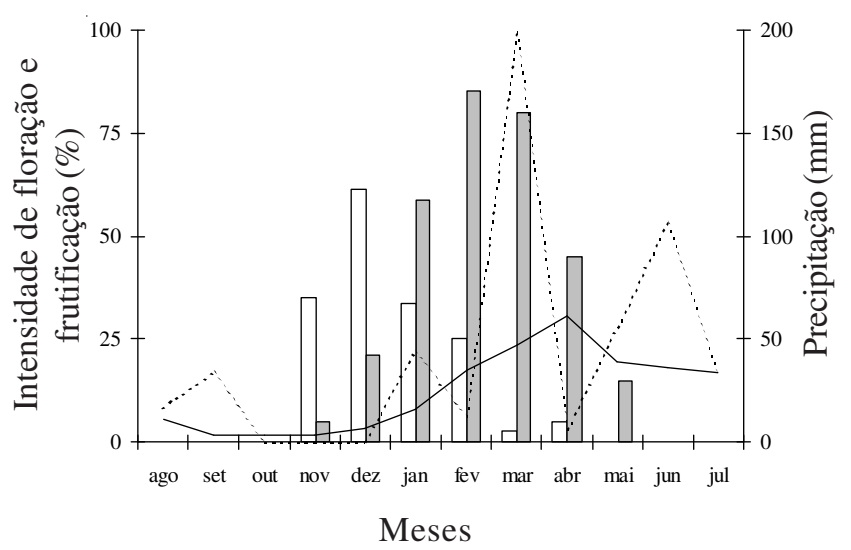

Figura 1. Intensidade de floração $(\square)$ e frutificação ( $\square$ ) de Spondias tuberosa durante o período de agosto/2004 a julho/2005 nos municípios de Boa Vista e Cabaceiras, PB. Precipitação mensal histórica do Município de Boa Vista (-) e no período de estudo de agosto/2004 a julho/2005 (---).

Figure 1. Intensity of flowering ( $\square$ ) and fruiting ( $\square$ ) of Spondias tuberosa from August/2004 to July/2005 in the municipalities of Boa Vista and Cabaceiras, Paraíba State, Brazil. Historical monthly precipitation of Boa Vista municipality (-) and precipitation during the studying period August/2004 to July/2005 (---). do total de flores hermafroditas, do meio para o ápice.

As flores dos dois tipos são pentâmeras, possuem cálice verde inconspícuo, cinco pétalas brancas e um androceu composto por dez estames, que estão distribuídos em dois grupos, cinco deles curtos, opostos às pétalas, e cinco longos, alternados com estas, todos com filetes brancos e anteras amarelas. As flores masculinas apresentam pistilódio e as flores hermafroditas apresentam gineceu pentacarpelar, pentalocular, com um único óvulo em um dos lóculos, e cinco estiletes livres entre si (figuras 2,3). O diâmetro da corola foi maior em flores hermafroditas $(U=60$, $P<0,001)$, assim como o tamanho do gineceu das flores hermafroditas em relação ao pistilódio das flores masculinas (tabela 1).

A antese iniciou-se por volta das $5 \mathrm{~h} 00 \mathrm{em}$ ambos os tipos florais, estando as flores completamente abertas em torno das $6 \mathrm{~h} 00$. As flores masculinas permaneceram abertas durante todo o dia, senescendo na manhã do dia seguinte, enquanto as hermafroditas permaneceram abertas e funcionais por dois ou três dias. Os resultados de crescimento de tubo polínico a partir de polinizações cruzadas indicam que os estigmas estão receptivos desde o início da antese, em flores do primeiro e segundo dia. As anteras tornam-se deiscentes desde o início da antese. As flores apresentam leve odor adocicado. No tratamento com vermelho neutro, as anteras ficaram bastante coradas e o nectário, levemente corado, em ambos os tipos florais.

Os estames mais curtos, que possuem anteras menores, apresentaram, em média, $411( \pm 87, n=40) \mathrm{e}$ $372( \pm 67, n=40)$ grãos de pólen por antera em flores hermafrodita e masculina, respectivamente, enquanto que os estames mais longos apresentaram $635( \pm 135$, $n=40)$ e $573( \pm 99, n=40)$ grãos de pólen por antera, respectivamente, não havendo diferença significativa em ambos os casos. Desse modo, o número total de grãos de pólen por flor não diferiu significativamente entre flores hermafroditas (média de 5.231 $\pm 1.019, n=8$ ) e masculinas (média de $4.721 \pm 635, n=8$ ). No entanto, os estames mais longos apresentaram maior quantidade de grãos de pólen em relação aos estames mais curtos dentro do mesmo tipo floral $(U=9, P<0,05)$. A viabilidade polínica foi de $98,4 \%$ em média $( \pm 1,55 \%)$, tendo sido semelhante entre os dois grupos de estames e entre os dois tipos florais.

Eficácia reprodutiva - Dentre as inflorescências marcadas para observação de polinização natural (controle), cerca de $36 \%$ delas formaram frutos, sendo que, destas, $90 \%$ formaram um fruto e $10 \%$, dois frutos. Portanto, considerando o total de flores hermafroditas 
destas inflorescências, apenas $0,58 \%$ formaram frutos (tabela 2). No tratamento de polinização cruzada para verificar a capacidade suporte de frutos por inflorescência, não houve formação de frutos, no entanto, houve início de desenvolvimento do ovário em quatro flores de uma única inflorescência. Apesar de não ter havido formação de frutos nesse tratamento, os resultados não diferiram significativamente em relação ao controle.

No tratamento de polinização cruzada utilizandose grãos de pólen provenientes de cada um dos dois tipos de doadores separadamente, não houve diferença significativa no número de frutos formados em cruzamentos com pólen de flores hermafroditas e flores masculinas (tabela 2), indicando que não houve diferença na fecundidade em função do doador de pólen.

Visitantes florais e disponibilidade de pólen - Foram registradas 17 espécies de insetos visitando as flores de $S$. tuberosa, sendo sete espécies de vespas, seis de abelhas e quatro de moscas (tabela 3). Polistes canadensis L. e Polybia ignobilis Haliday (Vespidae, Polistinae) pousavam na inflorescência e coletavam néctar posicionando a cabeça no centro da flor, contatando as anteras e os estigmas com o aparelho bucal (figura 4). Apis mellifera L., Scaptotrigona postica flavisetis Moure, Trigona fuscipennis Friese, (Apidae) ao pousarem em uma flor contatavam as anteras e os estigmas com a parte ventral do tórax (figura 5). Tanto as vespas quanto as abelhas realizavam a polinização durante a coleta do recurso floral.

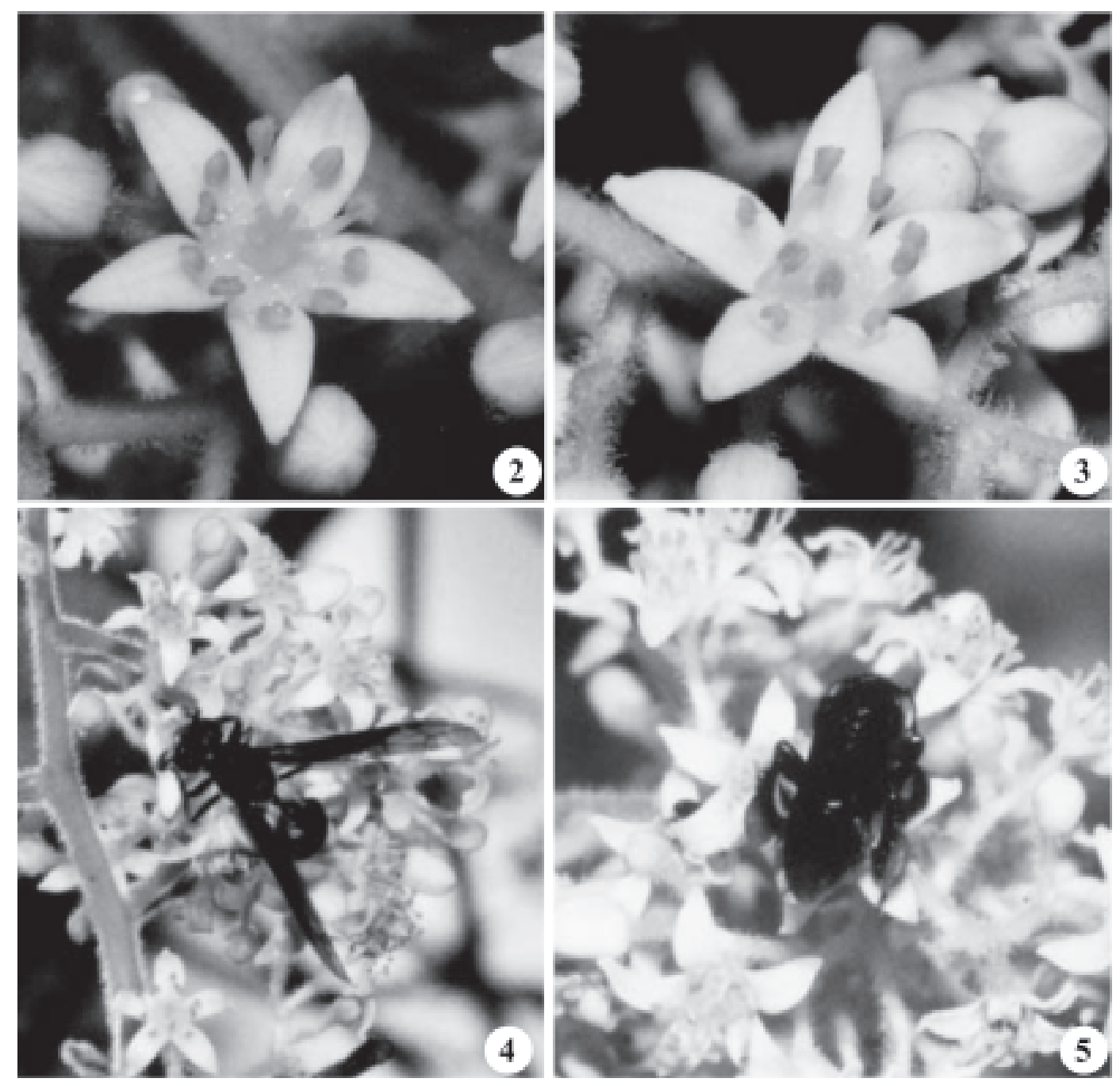

Figuras 2-5. Flores e visitantes florais de Spondias tuberosa na fazenda Dona Soledade, Paraíba, Brasil. 2. Flor hermafrodita. 3. Flor masculina. 4. Polybia ignobilis durante a coleta de néctar. 5. Trigona fuscipennis durante coleta de néctar.

Figure 2-5. Flowers and floral visitors of Spondias tuberosa, at the Dona Soledade farm, Paraíba State, Brazil. 2. Hermaphrodite flower. 3. Male flower. 4. Polybia ignobilis collecting nectar 5. Trigona fuscipennis collecting nectar. 
Tabela 1. Dimensões e quantidade de estruturas das flores hermafrodita e masculina de Spondias tuberosa, ocorrentes na fazenda Dona Soledade, Paraíba, Brasil (Número de partes florais = N).

Table 1. Measurement and number of structures of hermaphrodite and male flowers of Spondias tuberosa. Individuals occurring at the Dona Soledade farm, Paraíba State, Brazil (Number of floral parts = N).

\begin{tabular}{|c|c|c|c|c|c|}
\hline \multirow[t]{2}{*}{ Caracteres florais } & \multicolumn{2}{|c|}{ Flores hermafroditas } & \multicolumn{2}{|c|}{ Flores masculinas } & \multirow[t]{2}{*}{ Estatística } \\
\hline & $\mathrm{N}$ & $\begin{array}{l}\text { Dimensão } \\
\quad(\mathrm{mm})\end{array}$ & $\mathrm{N}$ & $\begin{array}{l}\text { Dimensão } \\
\text { (mm) }\end{array}$ & \\
\hline Cálice (sépalas) & 5 & & 5 & & \\
\hline Corola (pétalas)* & 5 & 8 & 5 & 7 & $U=60$ \\
\hline Estames curtos & 5 & 2 & 5 & 2 & \\
\hline Filete & 5 & 1,5 & 5 & 1,5 & \\
\hline Antera & 5 & 1 & 5 & 1 & \\
\hline Grãos de pólen** & $411 \pm 87$ & & $372 \pm 67$ & & n.s. \\
\hline Estames longos & 5 & 2,5 & 5 & 2,5 & \\
\hline Filete & 5 & 2 & 5 & 2 & \\
\hline Antera & 5 & 1 & 5 & 1 & \\
\hline Grãos de pólen** & $635 \pm 135$ & & $573 \pm 99$ & & n.s. \\
\hline Grãos de pólen/flor** & $5231 \pm 1019$ & & $4721 \pm 635$ & & n.s. \\
\hline Gineceu (carpelo/lóculos) & 5 & 2 & & & \\
\hline Óvulos/flor & 1 & & & & \\
\hline Pistilódio & 1 & & 1 & 1 & \\
\hline
\end{tabular}

*Diâmetro; **média $\pm s$; teste de Mann-Whitney $=U$; não significativo $=$ n.s.; $P<0,05$ ).

$*$ Diameter; $* *$ mean $\pm s$; Mann-Whitney test $=U$; not significant $=$ n.s.; $P<0.05$ ).

Polybia ruficeps xanthops Richards, Protonectarina sylveirae de Saussure, Protopolybia exigua de Saussure (Vespidae, Polistinae), Omicron sp. (Vespidae, Eumeninae), indeterminada sp.1 (Pompilidae) e as quatro espécies de moscas tocavam nas estruturas reprodutivas somente ocasionalmente quando se deslocavam na inflorescência de uma flor para outra. Duas espécies de abelhas, Frieseomelitta flavicornis Fabricius e Trigonisca pediculana Fabricius, ao visitarem as flores de $S$. tuberosa para coleta de néctar,

Tabela 2. Eficácia reprodutiva de Spondias tuberosa e formação de frutos a partir de diferentes doadores de pólen, na fazenda Dona Soledade, Paraíba, Brasil.

Table 2. Reproductive effectiveness of Spondias tuberosa and fruit set from different pollen donors, at the Dona Soledade farm, Paraíba State, Brazil.

\begin{tabular}{|c|c|c|c|c|}
\hline Tratamento & Inflorescências & Flores & Frutos & Sucesso $(\%)$ \\
\hline Polinização natural & 28 & 1.896 & 11 & 0,58 \\
\hline Polinização cruzada & 10 & 175 & $4 * *$ & - \\
\hline Eficácia reprodutiva & & & & - \\
\hline *Polinização natural & 88 & 176 & 2 & 1,14 \\
\hline *Polinização cruzada & 27 & 55 & 12 & 21,81 \\
\hline Eficácia reprodutiva & & & & 0,05 \\
\hline \multicolumn{5}{|l|}{ Polinização cruzada } \\
\hline 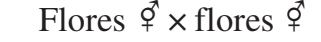 & 10 & 20 & 3 & 15 \\
\hline Flores $0^{\star} \times$ flores ${ }^{\dagger}$ & 10 & 20 & 1 & 5 \\
\hline
\end{tabular}

*Dados retirados de Leite (2006), **Ovário em início de desenvolvimento, sem atingir a maturidade.

*Data obtained by Leite (2006), **Ovary in initial development, without reaching the maturity. 
Tabela 3. Visitantes florais de Spondias tuberosa em uma área de caatinga na fazenda Dona Soledade, Paraíba, Brasil (LDP = Local de deposição do pólen no corpo do visitante; $\mathrm{PB}=$ partes bucais; VT = porção ventral do tórax; ND = não definido; $\mathrm{PO}$ = polinizador; $\mathrm{PI}=$ pilhador; $\mathrm{N}=$ néctar; $\mathrm{PL}=$ pólen; $\mathrm{I}=$ início de floração; $\mathrm{P}=$ pico de floração; $\mathrm{F}=$ fim de floração).

Table 3. Floral visitors of Spondia tuberosa in the "caatinga" area at the Dona Soledade farm, Paraíba State, Brazil (LDP = Place of pollen deposition; $\mathrm{PB}=$ mouth parts; $\mathrm{VT}=$ frontal part of the thorax; $\mathrm{ND}=$ without definition; $\mathrm{PO}=$ pollinator; $\mathrm{PI}=$ nectar thief; $\mathrm{N}=$ nectar; $\mathrm{PL}=$ pollen; $\mathrm{I}=$ flowering beginning; $\mathrm{P}=$ flowering peak; $\mathrm{F}=$ flowering end).

\begin{tabular}{|c|c|c|c|c|c|}
\hline Visitantes & $\begin{array}{l}\text { Comprimento } \\
\text { do corpo (mm) }\end{array}$ & LDP & $\begin{array}{l}\text { Resultado da } \\
\text { visita }\end{array}$ & $\begin{array}{l}\text { Recurso } \\
\text { coletado }\end{array}$ & $\begin{array}{l}\text { Estádio de } \\
\text { floração }\end{array}$ \\
\hline \multicolumn{6}{|l|}{ Abelhas } \\
\hline \multicolumn{6}{|l|}{ Apidae } \\
\hline Apis mellifera & 10 & VT & $\mathrm{PO}$ & $\mathrm{N}$ & $\mathrm{P}$ \\
\hline Frieseomelitta flavicornis & 5 & - & PI & $\mathrm{N}$ & $\mathrm{I} / \mathrm{P}$ \\
\hline Scaptotrigona postica flavisetis & 5 & VT & PO & $\mathrm{N}$ & $\mathrm{I} / \mathrm{P} / \mathrm{F}$ \\
\hline Trigona fuscipennis & 6 & VT & $\mathrm{PO}$ & $\mathrm{N}$ & $\mathrm{I} / \mathrm{P} / \mathrm{F}$ \\
\hline Trigonisca pediculana & 2 & - & PI & N/PL & $\mathrm{I} / \mathrm{P} / \mathrm{F}$ \\
\hline Xylocopa cf. frontalis & - & PB? & $\mathrm{PO}$ & $\mathrm{N}$ & $\mathrm{P}$ \\
\hline \multicolumn{6}{|l|}{ Vespas } \\
\hline \multicolumn{6}{|l|}{ Pompilidae } \\
\hline Indeterminada sp. 1 & 8 & ND & $\mathrm{PO}$ & $\mathrm{N}$ & $\mathrm{I} / \mathrm{P} / \mathrm{F}$ \\
\hline \multicolumn{6}{|l|}{ Vespidae, Eumeninae } \\
\hline Omicron sp. & 9 & ND & $\mathrm{PO}$ & $\mathrm{N}$ & $\mathrm{I} / \mathrm{P} / \mathrm{F}$ \\
\hline \multicolumn{6}{|l|}{ Vespidae, Polistinae } \\
\hline Polistes canadensis & 21 & PB & $\mathrm{PO}$ & $\mathrm{N}$ & $\mathrm{I} / \mathrm{P} / \mathrm{F}$ \\
\hline Polybia ignobilis & 13 & PB & $\mathrm{PO}$ & $\mathrm{N}$ & $\mathrm{I} / \mathrm{P}$ \\
\hline Polybia ruficeps xanthops & 9 & ND & $\mathrm{PO}$ & $\mathrm{N}$ & $\mathrm{I} / \mathrm{P} / \mathrm{F}$ \\
\hline Protonectarina sylveirae & 8 & ND & $\mathrm{PO}$ & $\mathrm{N}$ & $\mathrm{I} / \mathrm{P} / \mathrm{F}$ \\
\hline Protopolybia exigua & 6 & ND & $\mathrm{PO}$ & $\mathrm{N}$ & $\mathrm{I} / \mathrm{P} / \mathrm{F}$ \\
\hline \multicolumn{6}{|l|}{ Moscas } \\
\hline sp. 1 & 8 & ND & PO & $\mathrm{N}$ & $\mathrm{I} / \mathrm{P}$ \\
\hline sp. 2 & 6 & ND & $\mathrm{PO}$ & $\mathrm{N}$ & $\mathrm{I} / \mathrm{P} / \mathrm{F}$ \\
\hline sp. 3 & - & ND & $\mathrm{PO}$ & $\mathrm{N}$ & $\mathrm{I} / \mathrm{P} / \mathrm{F}$ \\
\hline sp. 4 & - & ND & PO & $\mathrm{N}$ & $\mathrm{I} / \mathrm{P} / \mathrm{F}$ \\
\hline
\end{tabular}

não contatavam as estruturas reprodutivas das flores, sendo consideradas como pilhadoras. Xylocopa cf. frontalis, ao visitar as flores de $S$. tuberosa, realizava a polinização tocando as estruturas reprodutivas das flores com o aparelho bucal. No entanto, por ter sido um visitante raro, cuja freqüência será discutida adiante, foi considerada polinizadora ocasional. Todas as espécies coletavam apenas néctar como recurso floral, com exceção de Trigonisca pediculana, que também coletava pólen.

As visitas às flores de Spondias tuberosa começavam por volta das 6 h00 e não foram mais registradas após as $16 \mathrm{~h} 00$, tanto no início como no pico de floração. No final da floração, as visitas terminavam mais cedo, por volta das $15 \mathrm{~h} 00$ (figura 6). O intervalo de maior frequiência de visitas foi aquele compreendido entre $6 \mathrm{~h} 00$ e $8 \mathrm{~h} 00$, durante todo o período de floração (figura 6). A freqüência dos visitantes florais está ilustrada na figura 7. As abelhas Scaptotrigona postica flavisetis e Trigona fuscipennis foram agrupadas, assim como as espécies de moscas, devido à difícil identificação no campo. O número de espécies visitantes e a freqüência das mesmas variaram de acordo com a fase da floração. No início e no fim de floração foram registradas 15 e 12 espécies de visitantes florais, sendo as vespas pequenas $(<10 \mathrm{~mm}$ de comprimento, ver tabela 4) e as abelhas $S$. postica flavisetis e T. fuscipennis as mais freqüentes, respectivamente (figura 7). No pico da floração, foi registrada a presença das 17 espécies visitantes, sendo $S$. postica flavisetis, T. fuscipennis e Polybia ignobilis, todas polinizadoras, as mais freqüentes (figura 7).

Scaptotrigona postica flavisetis e Trigona fuscipennis visitaram as flores de Spondias tuberosa 
no período entre $5 \mathrm{~h} 00$ e $8 \mathrm{~h} 00$, apresentando alta frequiência. No final da floração, as visitas dessas duas espécies prolongaram-se até as $10 \mathrm{~h} 00$. As espécies de vespas pequenas foram mais freqüentes no início

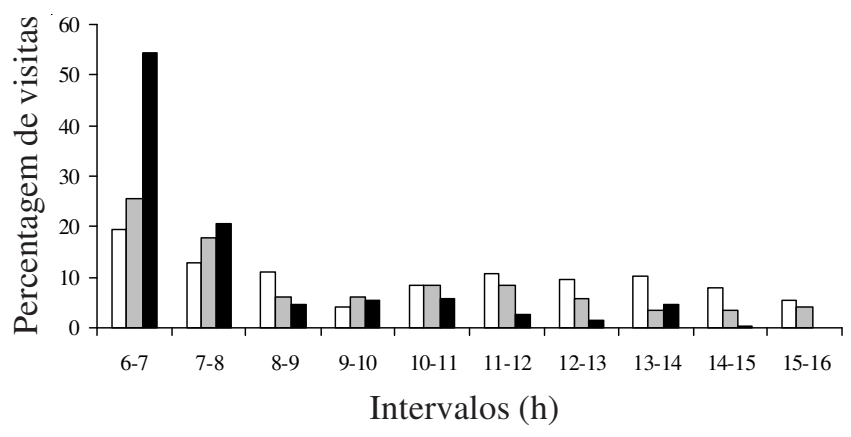

Figura 6. Percentual de visitas às flores de Spondias tuberosa ao longo do dia em indivíduos no início ( $\square$ ), pico

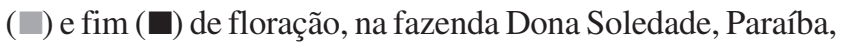
Brasil.

Figure 6. Frequency of visits to flowers of Spondias tuberosa during the day, at the beginning $(\square)$, peak ( $\square$ ) and at the end (घ) of blooming period, at the Dona Soledade farm, Paraíba State, Brazil.

Tabela 4. Polinizadores observados em Spondias tuberosa e Ziziphus joazeiro em uma área de caatinga na fazenda Dona Soledade, Paraíba, Brasil. Em destaque os polinizadores em comum $(++=$ principal polinizador; $+=$ polinizador; $\cdots=$ não polinizador; - = não visitante).

Table 4. Pollinators observed visiting flowers of Spondias tuberosa and Ziziphus joazeiro in a "caatinga" area at the Dona Soledade farm, Paraíba State, Brazil. Lines in gray refer to pollinators in common $(++=$ main pollinator; $+=$ pollinator; $\cdots=$ non pollinator; $-=$ non visitor $)$.

\begin{tabular}{lcc}
\hline Polinizadores & $\begin{array}{c}\text { Spondias } \\
\text { tuberosa }\end{array}$ & $\begin{array}{c}\text { Ziziphus } \\
\text { joazeiro }\end{array}$ \\
\hline Apis mellifera & + & + \\
Brachygastra lecheguana & - & + \\
Larra sp. & - & + \\
Moscas & + & $\ldots$ \\
Omicron sp. & + & - \\
Polistes canadensis & + & + \\
Polybia ignobilis & + & + \\
Polybia ruficeps xanthops & + & + \\
Polybia sp. grupo occidentalis & - & + \\
Pompilidae (sp. 1) & + & - \\
Protonectarina sylveirae & + & + \\
Protopolybia exigua & + & - \\
Scaptotrigona postica flavisetis & ++ & $\ldots$ \\
Trigona fuscipennis & + & - \\
Xylocopa cf. frontalis & + & \\
\hline
\end{tabular}

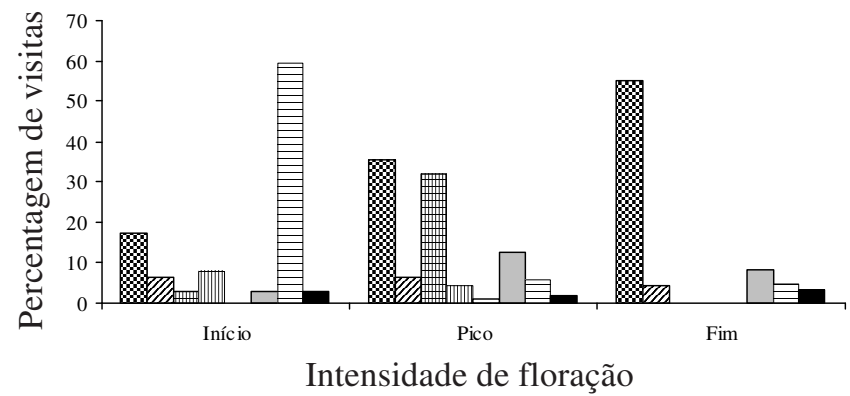

Figura 7. Percentual de visitas às flores de Spondias tuberosa das espécies visitantes no início, pico e fim de floração, na fazenda Dona Soledade, Paraíba, Brasil. Scaptotrigona postica flavisetis e Trigona fuscipennnis (淃), Trigonisca pediculana (菻), Polybia ignobilis (粗), Frieseomelitta flavicornis (隫), Apis mellifera $(\square)$, Moscas ( $\square$ ), Vespas pequenas (氜), Polistes canadensis (ם).

Figure 7. Frequency of the visitors to flowers of Spondias tuberosa in the beginning, peak and at the end of flowering, at the farm Dona Soledade, Paraíba State, Brasil. Scaptotrigona postica flavisetis and Trigona fuscipennnis (ख), Trigonisca pediculana (翟), Polybia

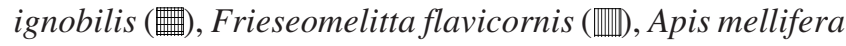

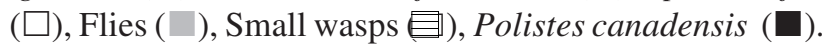

da floração, alcançando suas taxas mais altas entre $11 \mathrm{~h} 00$ e $16 \mathrm{~h} 00$ e contribuindo com $59,62 \%$ do total de visitas (figura 7). No pico de floração, essas espécies diminuíram suas freqüências, provavelmente devido ao maior número de espécies de visitantes florais. Nessa fase, Polybia ignobilis apresentou o segundo maior percentual de visitas, correspondendo a $31,92 \%$ do total, menor apenas do que o apresentado por $S$. postica flavisetis e T. fuscipennis que, juntas, representaram $35,54 \%$ do total de visitas (figura 7). O período de maior freqüência de $P$. ignobilis ocorreu entre 9 h00 e $13 \mathrm{~h} 00$, durante o pico da floração. No final da floração, as espécies de moscas foram as mais freqüentes entre $8 \mathrm{~h} 00$ e $12 \mathrm{~h} 00$ sendo responsáveis por $11,19 \%$ do total de visitas, enquanto que $S$. postica flavisetis e T. fuscipennis contribuíram com 72,56\% do total de visitas dessa fase (figura 7). As espécies A. mellifera (1,07\% do total de visitas) e Xylocopa cf. frontalis $(0,11 \%$ do total de visitas) só foram registradas no pico de floração e as demais espécies mantiveram os seus percentuais de visitas nas três fases de floração.

A quantidade de grãos de pólen disponível por flor de Spondias tuberosa decresceu substancialmente logo nas primeiras horas da antese (figura 8A), momento em que o número de visitas às flores atingiu o seu pico 


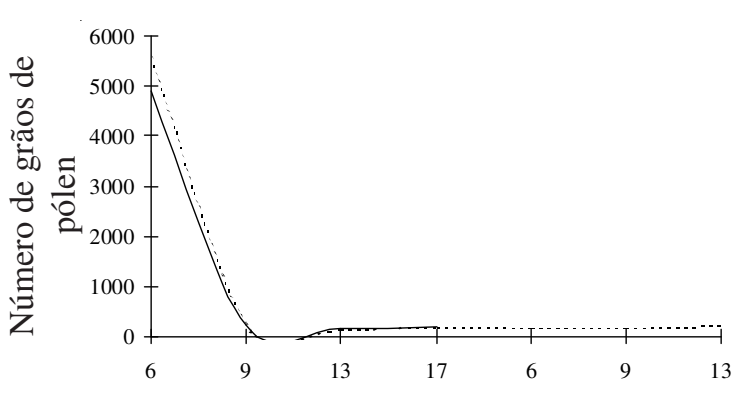

A

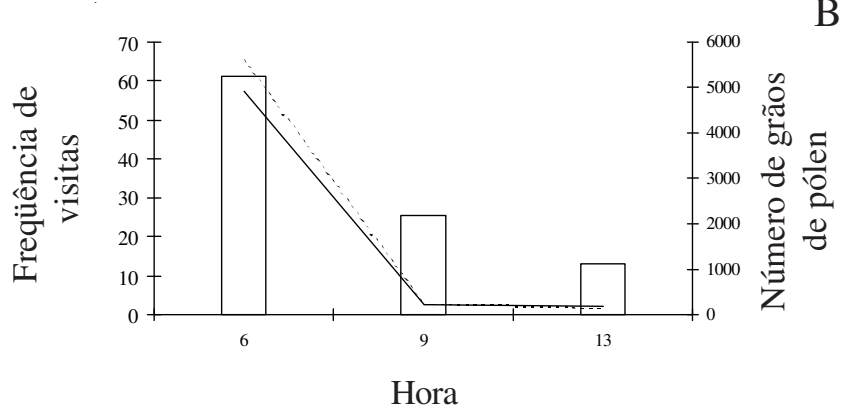

Figura 8. Disponibilidade de pólen em flores de Spondias tuberosa durante a antese floral (A) e em relação à frequiência de visitas (B). Grãos de pólen de flores hermafroditas (---), grãos de pólen de flores masculinas (-), freqüência de visitas ( $\square$ ).

Figure 8. Pollen availability in flowers of Spondias tuberosa during the anthesis (A) and in relation to the frequency of visits (B). Pollen grains of hermaphrodite flowers (---), pollen grains of male flowers (-), frequency of visits $(\square)$.

(figura 8B). Após as 9h00 o número de grãos de pólen por flor se manteve constante (figura 8), sendo a quantidade disponível extremamente baixa.

A similaridade entre os polinizadores de Spondias tuberosa e os de Ziziphus joazeiro foi de ca. de $30 \%$ (coeficiente de Jaccard $=0,28$ ). Cinco espécies de visitantes foram comuns a $S$. tuberosa e $Z$. joazeiro: Apis mellifera, Polistes canadensis, Polybia ignobilis, P. ruficeps xanthops e Protonectarina sylveirae (tabela 4). Entre os tratamentos de formação natural de frutos, não houve diferença estatística nas três diferentes situações: (1) período em que apenas Spondias tuberosa estava em floração; (2) período em que apenas Ziziphus joazeiro estava em floração e (3) período em que ambas as espécies estavam floridas (tabela 5).

\section{Discussão}

Fenologia reprodutiva e biologia floral - As fenofases de floração e frutificação de Spondias tuberosa
Tabela 5. Formação natural de frutos de Spondias tuberosa e de Ziziphus joazeiro na fazenda Dona Soledade, Paraíba, Brasil, em diferentes situações: $1=$ período em que apenas S. tuberosa estava em floração; $2=$ período em que apenas $Z$. joazeiro estava em floração; e $3=$ período em que ambas as espécies estavam floridas.

Table 5. Natural fruit set of Spondias tuberosa and Ziziphus joazeiro at the Dona Soledade farm, Paraíba State, Brazil, in different situations: 1 = period when only $S$. tuberosa was in blooming; 2 = period when only $Z$. joazeiro was in flowering; and $3=$ period when both species were in blooming.

\begin{tabular}{lcc}
\hline Tratamento & $\begin{array}{c}\text { Inflorescências/ } \\
\text { Flores/Frutos }\end{array}$ & $\begin{array}{c}\text { Sucesso } \\
(\%)\end{array}$ \\
\hline 1. Spondias tuberosa & $13 / 826 / 2$ & $0,2^{\mathrm{a}}$ \\
2. Ziziphus joazeiro & $15 / 191 / 0$ & $0^{\mathrm{b}}$ \\
3. Spondias tuberosa & $15 / 1070 / 9$ & $0,8^{\mathrm{a}}$ \\
Ziziphus joazeiro & $15 / 590 / 10$ & $1,7^{\mathrm{b}}$ \\
\hline
\end{tabular}

$\mathrm{a}=\chi^{2}=2,9 ; g l=1 ; P=0,16$;

$\left.\mathrm{b}=\chi^{2}=3,2 ; g l=1 ; P=0,15\right)$.

apresentaram padrão do tipo cornucopia sensu Gentry (1974) e anual de acordo com a classificação de Newstrom et al. (1994), pois os eventos ocorreram em poucas semanas e uma única vez no intervalo de um ano. A sazonalidade nos eventos reprodutivos é comum para espécies de caatinga (Machado et al. 1997, Griz \& Machado 2001, Barbosa et al. 2003), sendo influenciada principalmente pela precipitação (Machado et al. 1997), como foi o caso de S. tuberosa que floresceu no fim do período seco e início das chuvas. A frutificação ocorrendo no período chuvoso, como em S. tuberosa, pode favorecer a dispersão das sementes e o estabelecimento de plântulas (Bawa 1983, Primack 1987). Griz e Machado (2001) também observaram frutificação de Spondias tuberosa na estação úmida, no Município de Alagoinha, Pernambuco.

A maioria das flores hermafroditas de Spondias tuberosa foi produzida no estágio inicial do desenvolvimento das inflorescências, localizando-se no meio e no ápice da inflorescência, com quantidade de pólen e viabilidade polínica semelhantes às das flores masculinas. Estes resultados contrastam com o padrão encontrado por Symon (1979) para espécies andromonóicas do gênero Solanum (Solanaceae). Segundo esse autor, as flores hermafroditas também eram produzidas mais cedo, mas em menor número, apresentando menor quantidade ou qualidade de grãos de pólen, localizando-se na base da inflorescência. Uma vez que em Spondias tuberosa o número de flores 
hermafroditas e masculinas é semelhante, a grande quantidade de grãos de pólen com alta viabilidade em flores hermafroditas pode aumentar a expressão sexual masculina. A andromonoicia pode ser vantajosa, particularmente quando o custo da maturação de frutos é alto, como em espécies zoocóricas, e o número de flores masculinas é maior do que o número de flores que podem desenvolver frutos (Diggle 1993). O aumento da expressão sexual masculina também pode favorecer polinizações cruzadas através do aumento do fluxo polínico, principalmente em espécies auto-incompatíveis (Symon 1979, Medan \& D'Ambrogio 1998), como é o caso de Spondias tuberosa (Leite 2006).

$\mathrm{O}$ fato das flores hermafroditas produzirem grande quantidade de pólen com alta viabilidade pode também estar relacionado à questão de Spondias tuberosa estar incluída em um grupo basal dentro da família Anacardiaceae (Pell 2004). Considerando que a andromonoicia é um caráter basal entre as angiospermas, podendo evoluir para a dioicia (Lloyd 1972, Symon 1979), as espécies andromonóicas tendem a apresentar flores hermafroditas com grãos de pólen em menor número e com baixa qualidade (Symon 1979), sugerindo que $S$. tuberosa esteja em um estado mais basal em relação a outras espécies andromonóicas da família Anacardiaceae, uma vez que esta espécie apresentou flores hermafroditas com grande número de grãos de pólen e alta viabilidade polínica.

Eficácia reprodutiva - A baixa produção de frutos em relação ao número de flores, observada em Spondias tuberosa, pode estar relacionada a fatores extrínsecos, tais como recursos limitantes do ambiente (Stephenson 1981), e/ou intrínsecos, tal como frutos zoocóricos de alto valor energético, uma vez que foi observado o aborto de frutos jovens. Além disso, o baixo percentual de frutos formados naturalmente deve também estar relacionado à quantidade excessiva de flores produzidas em $S$. tuberosa.

A não formação de frutos no tratamento de polinização cruzada pode ser devida à distribuição limitante de recursos, uma vez que foram observados quatro ovários em desenvolvimento inicial de frutos em uma única inflorescência e, sob condições naturais, $S$. tuberosa produziu apenas um ou raramente dois frutos por inflorescência. Leite (2006) observou formação de frutos através de polinização cruzada quando foram manipuladas apenas duas flores por inflorescência, sendo, neste caso, possível calcular a eficácia reprodutiva (tabela 2), que é um indicativo de eficiência dos polinizadores (Zapata \& Arroyo 1978). Entretanto, os polinizadores devem promover alta taxa de geitonogamia, contribuindo para a baixa produção de frutos sob condições naturais, uma vez que $S$. tuberosa é auto-incompatível (Leite 2006).

Visitantes florais e disponibilidade de pólen - Dentre os visitantes florais de Spondias tuberosa, pode-se considerar as abelhas os principais polinizadores. Apesar de o grupo de vespas apresentar o maior número de espécies polinizadoras (tabela 4) e das flores de $S$. tuberosa apresentarem atributos (cores claras, néctar como recurso floral, corola curta permitindo fácil acesso ao néctar, emissão de odor adocicado) que permitem incluir a espécie na síndrome de polinização por vespas (sensu Faegri \& Pij1 1979, Endress 1994, Proctor et al. 1996), estas foram consideradas polinizadores secundários, com exceção de Polybia ignobilis. A alta frequiência de abelhas no início da manhã, associada ao acentuado decréscimo da quantidade de grãos de pólen disponível nesse mesmo horário, pode indicar maior atuação na polinização de $S$. tuberosa pelo grupo de abelhas durante as primeiras horas de antese. Após esse horário, a quantidade de pólen mantém-se constante, mesmo havendo razoável número de visitas, o que pode indicar, de forma geral, que os outros visitantes florais, vespas e moscas, tenham pequeno papel na polinização de $S$. tuberosa. No entanto, no início de floração, as pequenas vespas podem atuar na polinização, uma vez que foram o grupo que apresentou maior percentual de visitas nesse período.

O grupo composto pelas abelhas Scaptotrigona postica flavisetis e Trigona fuscipennis (Meliponini) foram os principais polinizadores de Spondias tuberosa nos três estádios de floração, uma vez que apresentaram alta freqüência de visitas no início da manhã, quando há maior quantidade de grãos de pólen disponível. Marinho et al. (2002) apontaram $S$. tuberosa como importante fonte de recurso para abelhas da tribo Meliponini, que são utilizadas por meliponicultores rurais nordestinos para produção de mel. Por sua vez, Aguiar et al. (1995) e Aguiar (2003) registraram Frieseomelitta doederleini Friese e Dialictus opacus Moure visitando flores de $S$. tuberosa em Itatim, Bahia, e em São João do Cariri, Paraíba, respectivamente, no entanto, essas abelhas não foram observadas no presente estudo. A vespa Polybia ignobilis também desempenhou importante papel na polinização de $S$. tuberosa durante o pico de floração, pois visitava as flores legitimamente, com alta freqüência, efetuando a polinização em todas as visitas.

Apesar de Spondias tuberosa e Ziziphus joazeiro (Nadia 2005) apresentarem síndromes de polinização semelhantes e a floração de ambas ocorrer na mesma época, essas espécies apresentaram baixo índice de 
similaridade entre os seus polinizadores. Dentre os cinco polinizadores compartilhados entre $S$. tuberosa e Z. joazeiro, apenas um, a vespa Polybia ignobilis, é considerado como principal para ambas as espécies. Devido a este fato, e por não ter havido diferença estatística na formação natural de frutos nas diversas situações apresentadas, pode-se dizer que o sucesso reprodutivo dessas espécies não foi afetado negativamente pela partilha de polinizadores. Ao contrário, a sincronia na floração de Spondias tuberosa e Ziziphus joazeiro pode aumentar a atração dos polinizadores, uma vez que se observou uma tendência de aumento do sucesso reprodutivo das espécies nesse período. Dessa forma, a ocorrência da floração de Spondias tuberosa e Ziziphus joazeiro na mesma época e a semelhança dos caracteres florais favorecem o sucesso reprodutivo dessas duas espécies, que por serem auto-incompatíveis (Leite 2006), dependem dos agentes polinizadores para sua reprodução.

Agradecimentos - À MSc. Ana Virgínia Leite (UFPE), pela constante ajuda nas atividades de campo. Ao MSc. André Santos (UFPE), pelo apoio no campo e auxílio nas análises estatísticas. À Dona Ana Maria Almeida, pela permissão para desenvolver este trabalho em áreas de sua propriedade. Ao Dr. Orlando Tobias Silveira (MPEG/PA), pela gentileza na identificação das espécies de vespas. Às Dras. Márcia Rêgo e Patrícia Albuquerque (UFMA), pela identificação das abelhas. Ao Dr. Marcelo Guerra (UFPE) por disponibilizar o microscópio de fluorescência. Ao Governo da Paraíba por disponibilizar os dados pluviométricos na internet. À Capes pela bolsa de mestrado concedida a T.L. Nadia. Ao CNPq pelo apoio financeiro e pelas bolsas de Produtividade em Pesquisa de I.C. Machado e A.V. Lopes.

\section{Referências bibliográficas}

AGUIAR, C.M.L. 2003. Utilização de recursos florais por abelhas (Hymenoptera, Apoidea) em uma área de Caatinga. Revista Brasileira de Zoologia 20:457-467.

AGUIAR, C.M.L., MARTINS, C.F. \& MOURA, A.C.A. 1995. Recursos florais utilizados por abelhas (Hymenoptera, Apoidea) em áreas de caatinga (São João do Cariri, Paraíba). Revista Nordestina de Biologia 10:101-117.

AYRES, M., AYRES JÚNIOR., M., AYRES, D.L. \& SANTOS, A.S. 2003. BioEstat 3.0. Aplicações estatísticas nas áreas das ciências biológicas e médicas. Sociedade Civil Mamirauá / MCT-CNPq / Conservation International, Belém.

BARBOSA, D.C.A., BARBOSA, M.C.A. \& LIMA, L.C.M. 2003. Fenologia de espécies lenhosas da caatinga. In Ecologia e conservação da caatinga (I.R. Leal, M. Tabarelli \& J.M.C. Silva, eds.). Universidade Federal de Pernambuco, Recife, p.657-693.
BARROS, L.M. 1995. Botânica, origem e distribuição geográfica. In Cajucultura: Modernas Técnicas de Produção (J.P.P. Araújo \& V.V. Silva, orgs.). Embrapa/ CNPAT, Fortaleza, p.55-71.

BARROSO, G.M. 1991. Sistemática de Angiospermas do Brasil. v.2. Imprensa Universitária, Viçosa.

BAWA, K.S. 1983. Patterns of flowering in tropical plants. In Handbook of experimental pollination biology (C.E. Jones \& R.J. Little, eds.). Van Nostrand Reinhold, New York, p.394-410.

BENCKE, C.S.C. \& MORELLATO, L.P.C. 2002. Comparação de dois métodos de avaliação da fenologia de plantas, sua interpretação e representação. Revista Brasileira de Botânica 25:269-275.

CAMPBELL, D.R. 1985. Pollinator sharing and seed set of Stellaria pubera: competition for pollination. Ecology 66:544-553.

CAVALCANTI, N.B., RESENDE, G.M. \& BRITO, L.T.L. 1999. Desenvolvimento do imbuzeiro (Spondias tuberosa Arr. Cam.) na região semi-árida do Nordeste brasileiro. Ciência e Agrotecnologia 23:212-213.

CAVALCANTI, N.B., RESENDE, G.M. \& BRITO, L.T.L. 2000. Processamento do fruto do imbuzeiro (Spondias tuberosa Arr. Cam.). Ciência e Agrotecnologia 24:252-259.

DAFNI, A. 1992. Pollination ecology: a practical approach. Oxford University Press, New York.

DIGGLE, P.K. 1993. Developmental plasticity, genetic variation, and the evolution of andromonoecy in Solanum hirtum (Solanaceae). American Journal of Botany 80:967-973.

DRUMOND, M.A., NASCIMENTO, C.E.S. \& MORGADO, L.B. 2001. Desenvolvimento inicial do umbuzeiro (Spondias tuberosa Arruda) no semi-árido pernambucano. In III Anais do Simpósio brasileiro de captação de água de chuva no semi-árido (J. Gnadlinger, ed.). Associação brasileira de captação e manejo de água de chuva, Campina Grande. CD-ROM.

ENDRESS, P.K. 1994. Diversity and evolutionary biology of tropical flowers. Cambridge University Press, Cambridge.

EPSTEIN, L. 1998. A riqueza do umbuzeiro. Bahia Agrícola 2:31-34.

FAEGRI, K. \& PIJL, L.VAN DER. 1979. The principles of pollination ecology. Pergamon Press, Oxford.

FOURNIER, L.A. 1974. Un metodo cuantitativo para la medición de características fenologicas en árboles. Turrialba 24:422-423.

GENTRY, A.H. 1974. Flowering phenology and diversity in tropical Bignoniaceae. Biotropica 6:64-68.

GIULIETTI,A.M., HARLEY, R.M., QUEIROZ,L.P., BARBOSA, M.R.V., BOCAGE NETA, A.L. \& FIGUEIREDO, M.A. 2002. Espécies endêmicas da caatinga. In Vegetação \& flora da caatinga (E.V.S.B. Sampaio, A.M. Giulietti, J. Virgínio \& C.F.L. Gamarra-Rojas, eds.). Associação Plantas do Nordeste - APNE, Centro Nordestino de Informação sobre Plantas - CNIP, Recife, p.103-115. 
GOVERNO DA PARAÍBA. 2005. Disponível na Internet http://www.paraiba.pb.gov.br. (acesso em 15/03/2005).

GRIZ, L.M.S. \& MACHADO, I.C.S. 2001. Fruiting phenology and seed dispersal syndromes in caatinga, a tropical dry forest in the northeast of Brazil. Journal of Tropical Ecology 17:303-321.

KEARNS, C.A. \& INOUYE, D.W. 1993. Techniques for pollination biologists. University Press of Colorado, Colorado.

KREBS, C.J. 1989. Ecological methodology. University of British Columbia, New York.

LEDERMAN, I.E., BEZERRA, J.E.F., ASCHOFF, M.N.A., SOUSA, I.A.M. \& MOURA, R.J.M. 1992. Oferta e procedência de frutas tropicais nativas e exóticas na CEASA - Pernambuco. Revista Brasileira de Fruticultura 14:203-209.

LEITE, A.V.L. 2006. Sistema reprodutivo em plantas da caatinga: evidências de um padrão. Tese de doutorado, Universidade Federal de Pernambuco, Recife.

LLOYD, D.G. 1972. Breeding systems in Cotula L. (Compositae, Anthemideae). New Phytology 71:1181-1194.

LORENZI, H. 1998. Árvores brasileiras: manual de identificação e cultivo de plantas arbóreas do Brasil. v.1. Editora Plantarum, Nova Odessa.

MACHADO, I.C.S., BARROS, L.M. \& SAMPAIO, E.V.S.B. 1997. Phenology of caatinga species at Serra Talhada, PE, northeastern Brasil. Biotropica 29:57-68.

MARINHO, I.V., FREITAS, M.F., ZANELLA, F.C.V. \& CALDAS, A.L. 2002. Espécies vegetais da caatinga utilizadas pelas abelhas indígenas sem ferrão como fonte de recursos e local de nidificação. In Anais I Congresso Brasileiro de Extensão Universitária (A. Ciacchi, A.M. Figueirêdo \& L.F.G. Ferreira, orgs.). Fórum de PróReitores de Extensão das Universidades Públicas Brasileiras, João Pessoa. CD-ROM.

MARTIN, F.W. 1959. Staining and observing pollen tubes in the style by means of fluorescence. Stain Technology 34:125-128.

MEDAN, D. \& D'AMBROGIO, A.C. 1998. Reproductive biology of the andromonoecious shrub Trevoa quinquenervia (Rhamnaceae). Botanical Journal of the Linnean Society 126:191-206.
NADIA, T.L. 2005. Sistemas de polinização de duas espécies frutíferas e endêmicas da Caatinga: Ziziphus joazeiro Mart. (Rhamnaceae) e Spondias tuberosa Arruda (Anacardiaceae). Dissertação de mestrado, Universidade Federal de Pernambuco, Recife.

NEWSTROM, L.E., FRANKIE, G.W. \& BAKER, H.G. 1994. A new classification for plant phenology based on flowering patterns in lowland Tropical Rain Forest trees at La Selva, Costa Rica. Biotropica 26:141-159.

PELL, S.K. 2004. Molecular systematics of the cashew family (Anacardiaceae). Dissertation, Louisiana State University and Agricultural and Mechanical College, Baton Rouge.

PRADO, D.E. 2003. As caatingas da América do Sul. In Ecologia e conservação da caatinga (I.R. Leal, M. Tabarelli \& J.M.C. Silva, eds.). Universidade Federal de Pernambuco, Recife, p.3-73.

PRIMACK, R.B. 1987. Relationships among flowers, fruits, and seeds. Annual Review of Ecology and Systematics 18:409-430.

PROCTOR, M., YEO, P. \& LACK, A. 1996. The natural history of pollination. Timber Press, Oregon.

RADFORD, A.E., DICKINSON, W.C., MASSEY, J.R. \& BELL, C.R. 1974. Vascular plant systematics. Harper \& Row Publishers, New York.

SCHEMSKE, D.W. 1981. Floral convergence and pollinator sharing in two bee-pollinated tropical herbs. Ecology 62:946-954.

SOKAL, R.R. \& ROHLF, F.G. 1995. Biometry. W.F. Freeman and Company, New York.

STEPHENSON, A.G. 1981. Flower and fruit abortion: proximate causes and ultimate functions. Annual Review of Ecology and Systematics 12:253-279.

SYMON, D.E. 1979. Sex forms in Solanum (Solanaceae) and the role of pollen collecting insects. In The biology and taxonomy of the Solanaceae, (J.G. Hawkes, R.N. Lester \& A.D. Skelding, eds.). Academic Press, London, p.385-398.

VOGEL, S. 1990. The role of scent glands in pollination. Amerind Publishing, New Delhi.

ZAPATA, T.R. \& ARROYO, M.T.K. 1978. Plant reproductive ecology of a secondary deciduous tropical forest in Venezuela. Biotropica 10:221-230. 